\title{
Simulation of Unglazed Solar Thermal Systems Integrated into Façade \& Combined with Ultra-Low Temperature District Heating \\ Mikel Lumbreras ${ }^{1}$, Roberto Garay ${ }^{1}$ \\ ${ }^{1}$ Building Technologies, Tecnalia, Spain
}

\begin{abstract}
This paper presents a theoretical simulation of thermal and economical assessment of façade integrated Solar Thermal (ST) in combination with Ultra Low Temperature (ULT) District-Heating (DH). This paper is in line with existing R\&D activities for the integration of unglazed systems in building envelopes, where facades provide an almost unexplored area for increasing solaractivated building envelopes. The combination of building-integrated solar systems with DH networks avoids the use of local storage and allows a novel combination of heat directionality, both from building to the heat grid and vice versa. A control algorithm for heat supply is presented, so that the performance of the overall system is the optimal.

Energetic results from solar simulations and economic assessment derived from the balance of building energy demand and solar production are presented. Over a fullyear period the proposed unglazed system produces as much as 50\% additional heat when compared with an isolated ST system and profitable economic metrics are reached over a simulation time of 20 years. Finally, it is concluded the heat sink nature of a DH network, for as many as $25-35 \%$ of the buildings connected to the DH includes ST system.
\end{abstract}

\section{Introduction}

In the European Union (EU), the $40 \%$ of the energy consumption corresponds to that consumed in buildings (L. Pérez-Lombard and J. Ortiz, 2008), becoming one of the main source of pollutants today. As a respond to that situation, from the European Commission (EC) by means of directives (EC, 2010 \& EC, 2012) regulates the energetic situation of the constructive sector, so that energetic requirements such as, the reduction of the $20 \%$ of the energy consumption, are fulfilled.

The main variable that affects to the heat demand for dwellings are the constructive characteristics of the buildings, considering transmittances in windows and envelopes and ventilation rates as the most representative for heat losses. According to Constantinos A. Balaras, K. Droutsa, E. Dascalaki and S. Kontoyiannidis (2005), the total existing building stock in Europe is estimated at 150 million dwellings, whereas the construction rate off new building is only 2 million every year. Maintaining this construction rate until 2050, it means that more than $72 \%$ of the total building stock is already built. As for the recent building stock in the $\mathrm{EU}$, around $70 \%$ of the residential stock was built before 1980, when energy efficiency requirements in buildings were not as stringent as today.

DH networks enables the integration of dwellings with different heating necessities in the same heat grid, enabling synergies between buildings with different consumption trends. The steady incorporation of nZEB (K. Loukaidou, A. Michopoulos and T. Zachariadis, 2017) in cities must be complemented with solutions for the existing building stock.

This paper studies the feasibility of incorporating unglazed solar collectors into the south façade of buildings and explores the differences by connection schemes to the ULT DH, presenting results for both energetic and economic performance. For this purpose, the state of art of district heating networks (and specially $\left.4^{\text {th }} \mathrm{GDH}\right)$ and solar systems are presented

\section{4th Generation ULT DH}

DH technology is identified as a key system for the decarbonisation of heat supply in Europe. Today, DH networks are responsible for covering the $13 \%$ of the total heat load in buildings in the EU (S. Werner, 2017). Nevertheless, there is still almost full dependency between fossil fuel and DH networks, with about $70 \%$ of the total energy production coming from fossil fuels.

Although most of the DH networks of today are based on Large Combined Heat \& Power (CHP) or large boilers with supply temperatures near to $100^{\circ} \mathrm{C}$, the lower availability of fossil fuels should enhance the transition to what is denominated as $4^{\text {th }}$ Generation DH (4GDH) $(H$. Lund, S. Werner, R., Svend Svendsen, J. Eric Thorsen, F. Hvelplund and B. Vad Mathiesen, 2017). The basic principles of the $4 \mathrm{GDH}$ is the reduction of supply temperatures up to ULT levels $\left(45 / 30^{\circ} \mathrm{C}\right)$ and decentralization of heat producers, allowing for a substantial increase in the use of RES such as Solar Thermal Systems and Waste Heat (WH) streams. In gross terms, the 4GDH is based on distributed heat sources along the network, allowing a precise heat control from buildings to networks and from producers to the networks. 


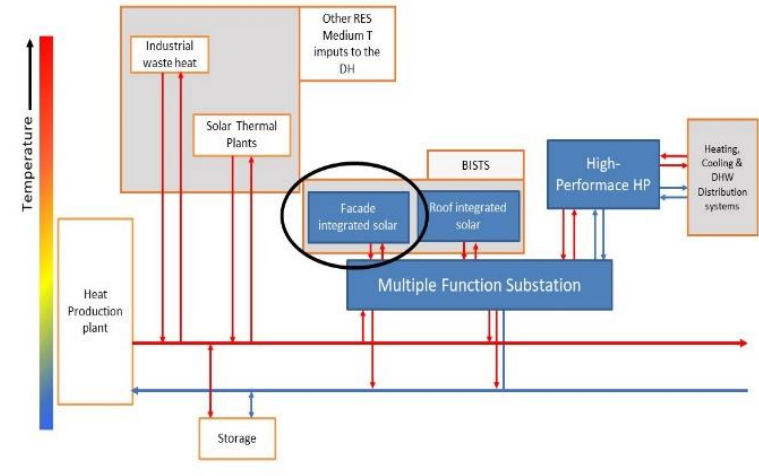

Figure 1: 4GDH distributed function scheme.

The reduction in working temperatures incorporates two main advantages. Firstly, due to the lower temperature gradient between supply and ambient dry bulb temperature, heat losses in distribution pipelines are also reduced, becoming a very important factor in large DH networks, where heat losses in distribution have an important role when designing the operation features. Secondly, 4GDH also allows the incorporation of low exergy distributed heat sources, such as ST energy and WH streams. H. Fang, J. Xia, K. Zhu, Y. Su and Y. Jiang (2013) studies the viability of using industrial WH in China for a DH network, reaching beneficial results for both stakeholders, pumping heat to the DH network and the improving the energy efficiency of the industry. Other important waste heat stream is the one coming from DataCentres (DC). M. Wahlroos, M. Pärssinen, J. Manner and S. Syri (2017) presents a case study in Finland, concluding that with high shares of waste heat in $\mathrm{DH}$, operational costs saving of $0.6-7.3 \%$ are reached.

\section{Solar Thermal energy}

Among all the RES that can be incorporated into a DH, this paper is focused on Solar Thermal energy. Solar Energy in the largest available RES in Earth (E. Kabir, P. Kumar, S. Kumar, Adedeji A. Adelodun and Ki-Hyun Kim, 2018), however, ST production and heat load have daily and seasonal variations due to transient and variable weather conditions.

There are several studies such as E. Kyriaki, E. Giama, A. Papadopoulou, V. Drosou and A.M. Papadopoulos (2017) \& S.V. Szokolay (2003) for ST systems used for SpaceHeating (SH) and Domestic Hot water (DHW) preparation purposes, most of them with positive economic returns. Usually, ST systems exceeds heat load in summer while heat load in winter, in most places exceeds the heat yield from collectors. This is why, ST systems are only sized to meet a fraction of the whole yearly heat load of buildings and rest of the load is fulfilled by fuel based traditional systems.

\section{Unglazed Façade Solar System}

This paper explores the Building Integrated Solar Thermal Systems (BISTS), excluding from this study the Large Solar systems installed far away from the urban area. As for the localization of BISTS, most of the studies are focused on systems integrated on roofs (M. Belusko,
W. Saman and F. Bruno, 2004). The main reasons for this are that, firstly, incident solar radiation falls upon directly the roofs of the building, whereas the south façade of a building only receives the $70 \%$ (A. Giovanardi, A. Passera, F. Zottele, R. Lollini, 2015) of the total radiation. However, in the winter, the south façade receives a greater solar insolation than the roofs due to the low solar height in these months. This reason, together with the necessity to meet the increased requirements for solar contribution, makes the façade a very promising solution.

Regarding thermal collectors' technology, three main types are suitable for BISTS application: Unglazed collectors, glazed collectors \& evacuated tube collectors. Although the particular coefficients of each type of collectors are different, the characterization of the performance of all of them is made by the same efficiency equation (J. A. Duffie, W. A. Beckman, 1980):

In the following equation, $T_{m}$ is the mean temperatures of heat fluid inside the ducts of the collector (can be reduced as the sum for the inlet and outlet temperature in each collector divided by two). $T_{a}$ corresponds to the dry bulb temperature $\left[{ }^{\circ} \mathrm{C}\right]$ in the environment and $\mathrm{G}_{\mathrm{T}}$ correspond to the total radiation in the incident surface $\left[\mathrm{W} / \mathrm{m}^{2}\right]$

$\eta_{c}(t)=\eta_{0}-a_{1} \frac{\left(T_{m}(t)-T_{a}(t)\right)}{G_{T}(t)}-a_{2} \frac{\left(T_{m}(t)-T_{a}(t)\right)^{2}}{G_{T}(t)}$

Where, $\{t=1,2,3 \ldots 8760\}$

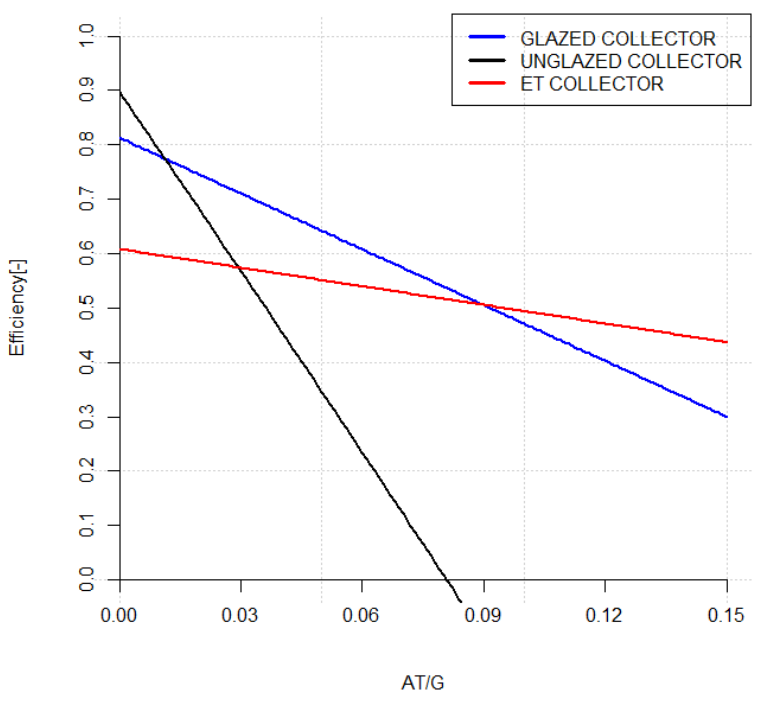

Figure 2: Efficiency ranges for ST collector types.

In Figure 2 is presented the efficiency curve for all collector types. $\Delta \mathrm{T}$ defined in the curve is representative of working temperatures, so high working temperatures are illustrated by high $\Delta \mathrm{T}$.

In essence, unglazed collectors present two main advantages for the considered application, among the other collector types. The first one is referred to the efficiency levels, since with low temperature difference 
(or low working temperatures) the collector with highest efficiency levels is the unglazed one. This becomes relatively important when the supply temperatures of the $\mathrm{DH}$ are reduced up to ULT temperature ranges. The other main advantage of these collectors concerns with constructive features. Facade integration of ST systems has been historically limited due to the need to accommodate glazed areas and tubular assembles in the architectural composition of buildings. Anyhow smart, but marginal integration solutions for vacuum tubes have been achieved in balconies or transparent areas (O’Hegarty, Kinnane \& McCormack, 2016).

Without glass covers and tubular covers, the unglazed collectors are the only one that can be integrated without modifying the aesthetics of the building. Specifically, the unglazed solar collector enables varied forms (shape, size and typology) and materials (colour, texture, transparency etc.).

In broad terms, it has to be considered that façades are the prominent image of the building. In the selection of ST technologies and their integration of Solar Thermal Façades (STF) this aspect needs to be taken into account. The existence of a wide-range of architectural facades requires delivery of a wide range of STF products, to ensure freedom of design intent. In the study by Garay R., Arregi B., Bonnamy P. \& Lopez, J. (2017) an experimental study is performed on unglazed ST collectors and their potential to deliver heat to HVAC systems in buildings. In this work, it is identified that facades are the biggest area where collectors can be installed, and that unglazed collectors are one of the most sensible alternatives to match ST production and architectural integration.

\section{DH \& ST Connection}

The subsystem in charge of connecting the DH network and the final consumption points (mainly, residential buildings) is the substation. The connection between ST and DH is totally influent in the performance of the whole system. Therefore, collectors' efficiency varies considerably if connected to the supply line or the return line of the DH. In case of considering an ULT DH, temperatures in the range of $45-50^{\circ} \mathrm{C}$ are representative of flowing temperatures, while $20-30^{\circ} \mathrm{C}$ are representative return lines.

There are multiple connection and operating possibilities when coupling ST and DH. The simplest substation scheme and the only one used so far is when the ST (basically, LST) is connected to the supply line with unidirectional heat flow from ST to the heat network. However, with the progress of substations, different variables have been developed, enabling different operating modes, such as, bi-directional heat flow and connection to return line of the $\mathrm{DH}$.

For this study, a novel design of a substation is considered, and the working pipeline-scheme is presented in the following figure. This substation enables the direct use from solar field to fill building demand, when temperature ranges permits. Secondly, as it is said before, bi-directional heat from $\mathrm{DH}$ to the building and from the building to the DH is permitted. Furthermore, for the optimization of the system, it is permitted to inject the heat, both to the supply line and to the return line of LTDH

For this purpose, reversible water pumps are incorporated, which permits pumping water in both directions.

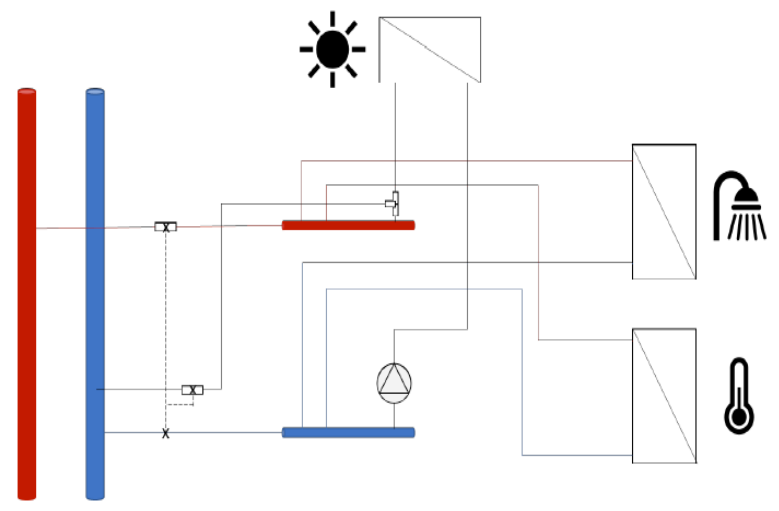

Figure 3: Substation concept for Solar Thermal DH.

As is could be concluded from the proposed connection scheme, the local heat storage typical of solar systems is avoided, since the DH networks acts as a heat supplier and as a heat sink at the same time.

\section{Methodology}

The paper explores energetic \& economic feasibility of façade integrated solar system connected to a ULT DH.

The methodology followed for the study is resumed in the following figure.

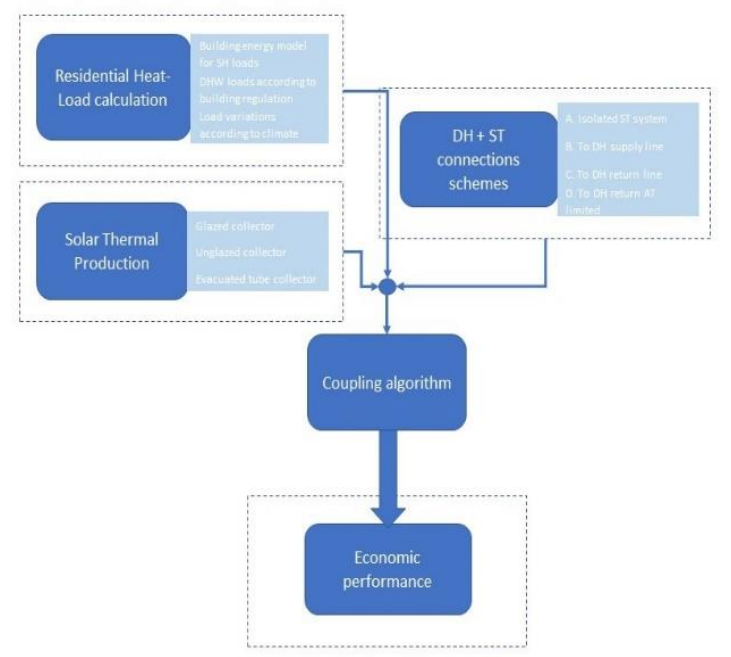

Figure 4: Methodology scheme followed in the study.

\section{Heat-Load \& District Modelling}

The process of the study starts with the characterization of building heating loads, which are totally dependent on external conditions. These external conditions are basically, climatic variables and constructive characteristics of buildings. For this study and in order to get useful results for a case study in Denmark, the climatic data for Copenhagen (Denmark) is used. This climatic data is obtained from Meteonorm and processed in 
TRNSYS so that incident radiation into different walls of a buildings are obtained.

A multi-rise building has been modelled in TRNSYS comprising 5 floors of $1250 \mathrm{~m}^{2}(50 \times 25 \mathrm{~m}$, with the largest surface facing the south and the north), with a window-towall ratio of $25 \%$. With the intention of developing the most realistic study, 3 different kind of buildings (B1, B2, B3) are defined in function of the age of construction. Different constructive characteristics are defined for each case, considering different transmittances in windows and walls of the building as well as ventilation rates. B1 buildings correspond to buildings built before 1980, B2 buildings correspond to buildings built from 1980 until 2010 and B3 are the same building as B1 but with renewed windows.

Table 1: Main constructive characteristics.

\begin{tabular}{|c|c|c|c|}
\hline Building & B1 & B2 & B3 \\
\hline UWALL $\left[\mathbf{W} / \mathbf{m}^{2}\right]$ & 1.99 & 0.93 & 1.99 \\
\hline UWINDOW[W/m²] & 5.73 & 2.26 & 2.01 \\
\hline $\begin{array}{c}\text { Infiltration rate } \\
{\left[\mathbf{h}^{-1}\right]}\end{array}$ & 0.4 & 0.3 & 0.4 \\
\hline $\begin{array}{c}\text { Ventilation rate } \\
{\left[\mathbf{h}^{-1}\right]} \\
\end{array}$ & 1.2 & 1.0 & 1.2 \\
\hline
\end{tabular}

The district is formed by a total of 160 buildings with the $30 \%$ of the building of type B1, $40 \%$ of type B2 and $30 \%$ of type B4.

The simulation is made for building separately and heat load for these residential buildings is divided into load for SH and DHW.

Regarding $\mathrm{DH}$, this load is totally dependent on constructive characteristics, so the modelling of this load is simulated in TRNSYS with a setpoint of indoor temperature of $20^{\circ} \mathrm{C}$. In this study the possibility to satisfy cooling demand is not considered. Considering the location of the simulation, cooling will not be as important as heating.

On the other hand, heat load for DHW has been calculated to national regulations. Considering a total useful area of $5000 \mathrm{~m}^{2}$, divided in apartments of $80 \mathrm{~m}^{2}$ and with 3 people in each apartment. As it can be seen, it is only an approximation to a real DHW heat load of an existing building. According to the calculation procedure, the mean consumption of DHW is about 22 litres of DHW per day and person and the minimum temperature necessarily reached is $60^{\circ} \mathrm{C}$. It has been also considered the variation of this load during the day, taking into account peak and peak-off hours.

\section{Solar System Simulation}

On the basis of the equation abovementioned and climatic data source, a model in $\mathrm{R}$ has been developed. In this model, serial arrangement of collectors has been simulated, monitoring temperatures in the entrance and the output of each collector.

The data of the collector used in this simulation is obtained from a real datasheet (Solar Collector Factsheet,
AS Kollektor) from where the coefficients of performance can be obtained.

A sensitivity analysis based on optimum utilization of the resources, in most cases, as early as the sixth collector in series, the increase in temperature of the water is not sufficient when compared to the investment required for its installation. It is concluded to simulate the installation into the facade of batteries of 6 collectors. From the coefficients of a singular collector, new battery coefficients are calculated from the regression from different working conditions. Simulations for different ambient conditions has been carried out, obtaining battery The limitation of space in the south façade of that building, the arrangement of solar batteries into the facades is supposed to cover the maximum empty space, referring to that where there are no windows. In this case, the solar system consists of 20 parallel circuits, covering a total of $240 \mathrm{~m}^{2}$ by solar systems.

\section{Coupling between Solar Production and Heat-Load}

The main problem in this study and one of the main novel concepts in the paper is the way in which the heat demand, the solar production and the heat from the $\mathrm{DH}$ are coupled.

Solar production and heating demands ( $\mathrm{SH}$ at least) have opposite trends and when the solar production is the highest in summer, the demand for $\mathrm{SH}$ is the lowest and vice versa. This phenomenon is usually solved by a seasonal heat storage if the solar system id large enough. However, in this study, the local storage is completely avoided, using the DH as the heat storage. In this way, the $\mathrm{DH}$ acts heat supplier and as store at the same time and the building acts as prosumer, a novel concept presented for $4 \mathrm{GDH}$. Buildings of the future wont only consume energy, but they will also produce heat for the grid.

The coupling algorithm for this particular case is the following: when the solar production is not enough to cover the full heating demand of a building, all the solar production is intended to cover the demand and the DH supplies the rest of necessary energy. The key of this system is when the solar production exceeds the heating demand. In these cases, the excess heat from ST system is injected to the $\mathrm{DH}$, in function of the temperature range of the moment, to the supply or to the return line of the DH. This way, it is possible to obtain an economic revenue from the excess heat sold to the $\mathrm{DH}$ owner. This algorithm is just for the first years of the 4GDH, considering that the heat network has still a few producers that may stabilize the whole network. There is another algorithm possibility, that is not considered for this study. It is based on that all the solar production is sold to the $\mathrm{DH}$ and all the heat demand is covered by the DH.

This study also comprises the possibility that the ULT DH can saturate, in other words, that the DH exceeds its capacity to absorb heat from distributed heat sources. To define the saturation levels of the $\mathrm{DH}$, a new variable is defined.

$$
\operatorname{Demand}_{D H}=\frac{\text { Demand }_{\text {building }}}{B S F[-]}
$$


here, the BSF correspond to the percentage of buildings that incorporates ST systems.

All in all, it is proposed a bidirectional heat flowing system allowed by the substation commented before and which permits to the system controlling heat supply.

\section{Initial budget}

Referring to economic calculation, the first step is to define the initial investment necessary for the installation of the proposed system. From the same data-sheet from the collector and the other economic data from Precio Centro Guadalajara (Visited in 2018), it has been made cost estimation, which is resumed in the following table, divided by the main concepts of the system. The initial investment (and all the economic study) is shown in $€$ and not in Denmark national monetary units, so that the results are more interpretable

Table 2: Initial budget estimation for solar installation.

\begin{tabular}{|c|c|c|}
\hline Concept & Main components & Quantity \\
\hline $\begin{array}{c}\text { Solar system } \\
\text { (BISTS) }\end{array}$ & $\begin{array}{c}\text { Solar collector, } \\
\text { support assembly to } \\
\text { the façade, water- } \\
\text { pump, valves etc. }\end{array}$ & $53.603,51 €$ \\
\hline $\begin{array}{c}\text { Primary circuit } \\
\text { (From substation } \\
\text { to the building) }\end{array}$ & $\begin{array}{c}\text { Water supply pumps, } \\
\text { pipelines, etc. }\end{array}$ & $6.695,93 €$ \\
\hline $\begin{array}{c}\text { Secondary (From } \\
\text { DH to the } \\
\text { substation) }\end{array}$ & $\begin{array}{c}\text { DH pipeline, Energy } \\
\text { meters, etc. }\end{array}$ & $1.722,56 €$ \\
\hline Substation & $\begin{array}{c}\text { Cost estimation for } \\
\text { the substation } \\
\text { detailed in }\end{array}$ & $3.660 €$ \\
\hline \multicolumn{2}{|c|}{ Total $(€ /$ Building) } & $\mathbf{6 5 . 6 8 2} €$ \\
\hline
\end{tabular}

\section{Economic metrics \& Energy Pricing}

Apart from the initial investment required in each case, this paper explores the economic evolution of the system against traditional benchmarks, in this case for obvious reason, it is compared against CHP based DH without any ST.

For this purpose, the operational costs along 20 years are calculated and evaluated by different economic metrics. The economic metric considered for this study are the discount Net Present Value (dNPV) and the Return of Investment (ROI). The equations that define each metrics are the followings:

$$
\begin{gathered}
d N P V=\sum_{i=1}^{T} \frac{Q_{i}}{(1+r)^{i}}-I_{0} \\
R O I=\frac{d N P V}{I_{0}}
\end{gathered}
$$

It is important to explain that all the calculation is made with the cash flow differences between the system proposed in this paper and the traditional benchmark. The interest rate considered for this study is $5 \%$, which can be regarded as a conservative interest. This way, the obtained results have improvement margin.

Moreover, the prices for the energy sources used for these economic metrics are expressed in the following table. The data for the energy pricing is obtained from (M. Galindo, C. Roger-Lacan, U. Gährs and V. Aumaitre, 2016) and the price for the heat sold to the DH is estimated to be from a $60 \%$ to the $90 \%$ of the real $\mathrm{DH}$ purchase heat. In real case studies, the price for selling the heat to a $\mathrm{DH}$ network must be agreed with the DH owner. In general, this price is set by the quality of the energy sold to the $\mathrm{DH}$, referring to temperature range and security of supply by mean of quality.

Table 3: Energy pricing for operational cost assessment.

\begin{tabular}{|c|c|c|c|}
\hline $\begin{array}{c}\text { Natural gas } \\
(€ / \text { kWh })\end{array}$ & $\begin{array}{c}\text { DH heat } \\
\text { purchase } \\
(€ / \text { kWh })\end{array}$ & \multicolumn{2}{|c|}{$\begin{array}{c}\text { DH heat selling } \\
(€ / \text { kWh })\end{array}$} \\
\hline \multirow{3}{*}{0,075} & \multirow{3}{*}{0,089} & $\mathbf{6 0 \%}$ & 0,0534 \\
\cline { 3 - 4 } & & $\mathbf{7 0 \%}$ & 0,0623 \\
\cline { 3 - 4 } & & $\mathbf{8 0 \%}$ & 0,0712 \\
\cline { 3 - 4 } & & $\mathbf{9 0 \%}$ & 0,0801 \\
\hline
\end{tabular}

\section{Results}

Following the same order as the methodology aforementioned, the results obtained are presented divided into two main groups. Energetic results and economics metrics.

\section{Energetic Results: Heat-Loads \& Heat-Production}

Firstly, the heat load for each building is presented with a daily frequency and it is shown the dependency between climatic variables and heating necessities and it can be also seen how the constructive characteristics influence the total heat consumption. For the sake of clarity, the results are presented for singular buildings.

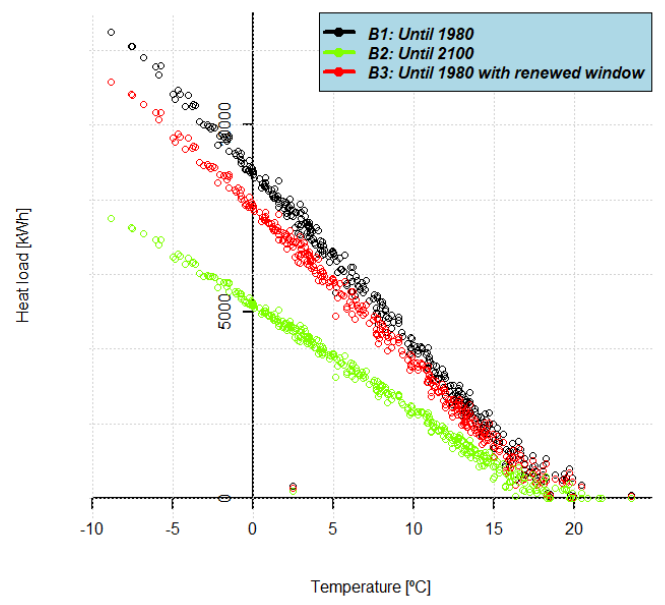

Figure 5: Heat-Load [kWh] vs ambient $T\left[{ }^{\circ} \mathrm{C}\right]$ for the 3 building types $B 1, B 2 \& B 3$. 
From the solar simulation model in $\mathrm{R}$, it is presented the monthly solar production. It is shown the difference of collectors' performance, with different connection schemes to the heat grid. These results are also shown in building scale.

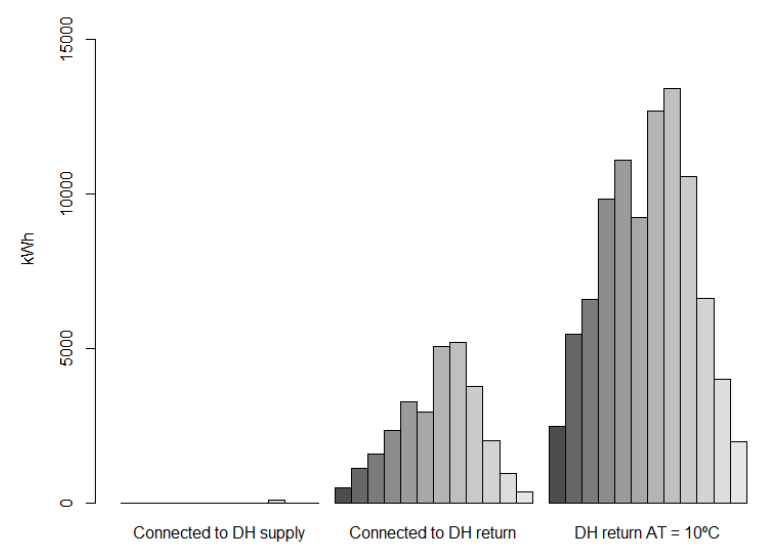

Figure 6: Monthly Solar production in $k W h$ in function of connection scheme to DH.

\section{Economic Results: Metrics}

As mentioned in the method of coupling the heat loads, solar energy production and heat from the ULT DH, the economic evolution of the overall system is calculated by mean of the economic metrics aforementioned.

As representative of the whole economic assessment study, it is shown the evolution of operational costs along 20 years since the installation.

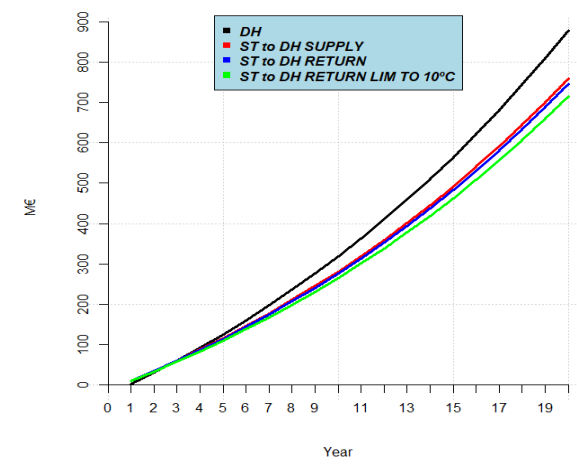

Figure 7: Cost evolution for the overall system along 20 years.

In next figure, and for shake of clarity, it is shown the detail of the first 5 years of the operational costs' evolution.

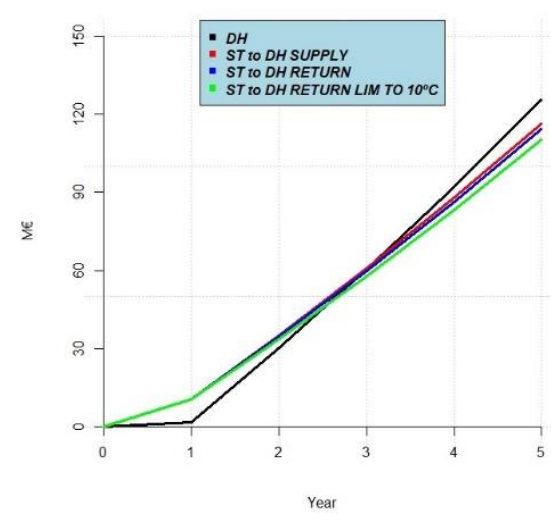

Figure 8: Detail of the first 5 years of the cost evolution. Regarding the economic metrics, ROI is a relative value for the dNPV, so that presenting these results the system can be considered to be represented. In the following table is resumed the ROI value for the case studies analysed in this article.

Table 4: ROI values [-] for the case studies

\begin{tabular}{|c|c|c|c|}
\hline ROI Values & Supply & Return & $\begin{array}{c}\text { Return AT } \\
\mathbf{= 1 0} \mathbf{~}^{\mathbf{C}}\end{array}$ \\
\hline $\mathbf{B S F}=\mathbf{0 \%}$ & 1.21 & 2.35 & 2.88 \\
\hline $\mathbf{B S F}=\mathbf{5 0 \%}$ & 1.19 & 2.10 & 2.34 \\
\hline
\end{tabular}

\section{Discussion}

In this work the possibility to incorporate unglazed solar thermal collectors in the context of future ULT DH is studied.

In general, the distributed solar thermal district heating seems to be a promising solution to implement with reasonable control strategies. The novel substation presented in this paper enables heat transfer in both direction, from the ST to DH and from DH to the building. Local thermal storage is completely avoided, and the DH pipeline enables heat delivery to the building and injection from ST in moments of overproduction. Regarding production levels, the unglazed collector shows great performance levels when it is not obliged to reach high temperatures. However, it is difficult for the unglazed collectors to reach DH supply temperatures, at least, in such climatic conditions. This is why, it is necessary to couple it with other heat sources with higher exergy level, such as high performance and locally deployed heat pumps or just the DH itself.

Note the difference between solar production when connecting to the supply line or to the return line. It can be concluded with actual technology of unglazed systems, that best results are obtained when the excess heat is injected into the return line of the network and the temperature of the fluid is controlled under restrictions not to overtake a limit and maintain high efficiency levels as much time as possible. When unglazed field is limited up to a AT of $10^{\circ} \mathrm{C}$, the solar energy doubles the one without limiting the temperature difference, reaching maximum of more $\% 200$. 
As for the payback times of the overall system, from figure 7 and figure 8 is concluded that in most cases the payback time will round 3 years.

Regarding economic metrics, the presented case study shows great feasibility if compared with DH without ST. All the ROI > 0 means that feasibility of the overall system converges to positive values and in most cases, the ROI is significantly higher.

Although the ST collector field incorporates relevant capital costs for the installation of the ST system, the connection to the DH avoids the need for large heat production systems to be installed for back-up, through reducing investments in auxiliaries, and reducing operational costs.

The main problem that may be faced by these installations is the capacity of the DH return line to absorb heat from ST when there are lots of distributed systems connected to them. Although, in actuality, this problem does not exist due to the development situation, in the future it will need to be taken into account to avoid the collapse of the DH network.

\section{Conclusion \& Further Work}

This paper has studied the technical and economic feasibility for the integration of unglazed ST collectors in buildings, and its connection to $\mathrm{DH}$ infrastructure.

This activity will be extended within the EU h2020 project RELaTED (2017). Within this project, among other activities, an unglazed ST system will be adapted for $\mathrm{DH}$ operation and tested under a controlled test environment in the north of Spain. This same system will be integrated in up to $4 \mathrm{DH}$ networks across Europe.

\section{Acknowledgement}

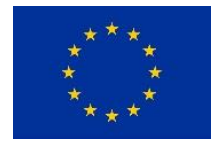

This project has received funding from the European Union's Horizon 2020 research and innovation programme under grant agreement No 768567.

\section{References}

Belusko M., Saman W., Bruno F., Roof integrated solar heating system with glazed collector (2004), Solar Energy, Volume 76, Issues 1-3, 2004, Pages 61-69, https://doi.org/10.1016/j.solener.2003.08.020.

Constantinos A., Balaras K., Droutsa E., Dascalaki S., Kontoyiannidis, (2005), Deterioration of European apartment buildings, Energy and Buildings, Volume 37, Issue 5, Pages515-527, https://doi.org/10.1016/j.enbuild.2004.09.010.

Duffie J. A., Beckman W. A. (1980), Solar engineering of thermal processes, Second edition, Pages 250-330.

Fang H., Xia J., Zhu K., Su Y., Jiang Y. (2013), Industrial waste heat utilization for low temperature district heating, Energy Policy, Volume 62, 2013, Pages 236246, https://doi.org/10.1016/j.enpol.2013.06.104.

Galindo M., Roger-Lacan C., Gährs U., Aumaitre V. (2016), Efficient district heating and cooling systems in the EU. ISBN 978-92-79-65048-2, ISSN 18319424, doi: 10.2760/371045.

Garay Martinez, R., Arregi Goikolea, B., Bonnamy, P., \& Lopez, J. (2017). Concept, development and thermal characterization of an unglazed solar thermal collector for façade integration. Dyna ingenieria e industria. 92. 466-472. 10.6036/8108.

Giovanardi A., Passera A., Zottele F., Lollini R. (2015) Integrated solar thermal façade system for building retrofit, Solar Energy, Volume 122, 2015, Pages 11001116 , https://doi.org/10.1016/j.solener.2015.10.034

Kabir E., Kumar P., Kumar S., Adedeji A. Adelodun, KiHyun Kim (2018), Solar energy: Potential and future prospects, Renewable and Sustainable Energy Reviews, Volume 82, Part 1, Pages 894-900, https://doi.org/10.1016/j.rser.2017.09.094.

Kyriaki E., Giama E., Papadopoulou A., Drosou V.,. Papadopoulos A.M (2017), Energy and Environmental Performance of Solar Thermal Systems in Hotel Buildings, Procedia Environmental Sciences, Volume 38,2017,Pages36-43, https://doi.org/10.1016/j.proenv.2017.03.072.

Loukaidou K., Michopoulos A., Zachariadis Th. (2017), Nearly-zero Energy Buildings: Cost-optimal Analysis of Building Envelope Characteristics, Procedia Environmental Sciences, Volume 38, 2017, Pages 2027, https://doi.org/10.1016/j.proenv.2017.03.069.

Lund H., Werner S., Svend Svendsen R., Eric Thorsen J., Hvelplund F., Vad Mathiesen B. (2017), 4th Generation District Heating (4GDH): Integrating smart thermal grids into future sustainable energy systems, Energy, Volume68,Pages1-11, https://doi.org/10.1016/j.energy.2014.02.089

O’Hegarty R., Kinnane O., \& McCormack S.J. (2016). Review and analysis of solar thermal façades. Solar Energy, Volume 135, pp 408-422, ISSN 0038-092X

Pérez-Lombard L., Ortiz J., Pout C. (2008), A review on buildings energy consumption information, Energy and Buildings, Volume 40, Issue 3, 2008, Pages 394 398, https://doi.org/10.1016/j.enbuild.2007.03.007

Szokolay S.V. (2003), Solar Energy in Buildings, In Encyclopedia of Physical Science and Technology (Third Edition), edited by Robert A. Meyers, Academic Press, New York, 2003, Pages 111-126, ISBN 9780122274107, https://doi.org/10.1016/B0-12227410-5/00700-6.

Wahlroos M., Pärssinen M., Manner J., Syri S. (2017), Utilizing data center waste heat in district heating Impacts on energy efficiency and prospects for lowtemperature district heating networks, Energy, Volume 140, Part 1, 2017, Pages 1228-1238, ISSN 0360-5442,

https://doi.org/10.1016/j.energy.2017.08.078. 
Werner S., International review of district heating and cooling (2017), Energy, Volume 137, Pages 617-631, , https://doi.org/10.1016/j.energy.2017.04.045.

EC, Directive 2010/31/EU of the European Parliament and of the Council of 19 May 2010 on the energy performance of buildings OJ L 153, 18.6.2010, p. 1335

EC, Directive 2012/27/EU of the European Parliament and of the Council of 25 October 2012 on energy efficiency, amending Directives 2009/125/EC and 2010/30/EU and repealing Directives 2004/8/EC and 2006/32/EC.
Precio centro Guadalajara [Price center Guadalajara]. Visited in 2018. Retrieved from http://preciocentro.com/tienda/productos-edicion2017/55-base-edificacion-urbanizacion-2017.html [CD-ROM].

Solar Collector Factsheet, Energie Solaire Kollektor AS, https://www.energiesolaire.com/jt_files/pdf/scf1209de.pdf (Visited in 2018). 